Brent, RL and Fawcett, LB: Developmental toxicology, drugs, and

fetal teratogenesis. In Reece EA, Hobbins JC (eds.) Clinical

Obstetrics: The Fetus and Mother, 3rd edition, Blackwell Publishing Inc., Malden, MA, Chapter 15, pp. 217-235, 2007.

\title{
Developmental toxicology, drugs, and fetal teratogenesis
}

Robert L. Brent and Lynda B. Fawcett

Reproductive problems encompass a multiplicity of diseases including sterility, infertility, abortion (miscarriage), stillbirth, congenital malformations (resulting from environmental or hereditary etiologies), fetal growth retardation, and prematurity. These clinical problems occur commonly in the general population and, therefore, environmental causes are not always easy to corroborate (Table 15.1). Severe congenital malformations occur in $3 \%$ of births; according to the Center for Disease Control, they include those birth defects that cause death, hospitalization, and mental retardation, and those that necessitate significant or repeated surgical procedures, are disfiguring, or interfere with physical performance. This means that each year in the USA, 120000 babies are born with severe birth defects. Genetic disease occurs in approximately $11 \%$ of births, and spontaneous mutations account for approximately $2-3 \%$ of genetic disease. This spontaneous mutation rate presents difficulties when determining the proportion of mutations that are induced from preconception exposure to environmental mutagens.

There have been dramatic advances in our understanding of the causes of human birth defects. In earlier times, superstition, ignorance, and prejudice played a major role in explaining why birth defects occurred. Reproductive problems have been viewed throughout history as diseases of affliction, along with cancer, psychiatric illness, and hereditary diseases. The stigma associated with birth defects has primitive beginnings and persists today; in the minds of many, even the most sophisticated, a birth defect is felt to be some form of punishment for previous misdeeds. ${ }^{1-4}$ Ancient Babylonian writings recount tales of mothers being put to death because they delivered malformed infants. In the seventeenth century, one George Spencer was slain by the Puritans in New Haven having been convicted of fathering a cyclopean pig; the Puritans were unable to differentiate between George Spencer's cataract and the malformed pig's cloudy cornea. ${ }^{1}$ More recently, the situation has been reversed and the responsibility for reproductive problems such as congenital malformations, infertility, abortions, and hereditary diseases is often blamed on others, for example, environmental agents dispensed by healthcare providers or utilized by employers. ${ }^{1,2}$

Reproductive problems alarm the public, the press, and scientists to a greater degree than many other diseases. Severely malformed children are disquieting to healthcare providers, especially if they are not experienced in dealing with such problems; no physician will be comfortable informing a family that their child was born without arms and legs. The objective evaluation of the environmental causes of reproductive diseases is clouded by the emotional climate that surrounds these diseases, resulting in the expression of partisan positions that either diminish or magnify the environmental risks. These nonobjective opinions can be expressed by scientists, the laity, or the press. ${ }^{5,6}$ It is the responsibility of every physician to be aware of the emotionally charged situation when a family has a child with a birth defect; an inadvertent comment from medical staff attending delivery can have grave consequences for the physician and the family. Comments such as, "Oh, you had a radiograph during your pregnancy," or "You did not tell me that you were prescribed tetracycline while you were pregnant," can direct the patient's family to an attorney rather than to a teratology or genetic counselor. .

At present, the etiology of congenital malformations can be divided into three categories: unknown, genetic, and environmental. Unfortunately, the largest group (65-75\%) has an unknown etiology, whereas the most common known cause is genetic (15-25\%). ${ }^{7-9}$ Environmental factors account for $10 \%$ of congenital malformations. Over 50 teratogenic environmental drugs, chemicals, and physical agents have been described ${ }^{9-12}$ by clinical dysmorphologists using modern epidemiological tools. ${ }^{13-19}$ The basic science and clinical rules for evaluating teratogenic risks have been established. ${ }^{20}$ The purpose of this chapter is to inform clinicians about environmental drugs, chemicals, and physical agents that have been documented to produce congenital malformations and reproductive effects, and to indicate that the multirude of teratogenic agents accounts for only a small proportion of malformations. 
Table 15.1 Background reproductive risks in pregnancy.

Reproductive risk

Frequency

Immunologically and clinically diagnosed spontaneous abortions per million conceptions

350000

Clinically recognized spontaneous abortions per million clinically recognized pregnancies

150000

Genetic diseases per million births:

110000

Multifactorial or polygenic genetic environmental interactions (i.e., neural tube defects, cleft lip, hypospadias,

90000

hyperlipidemia, diabetes)

Dominantly inherited disease (i.e., achondroplasia, Huntington's chorea, neurofibromatosis)

10000

Autosomal and sex-linked genetic disease (i.e., cystic fibrosis, hemophilia, sickle-cell disease, thalassemia)

1200

Cytogenetic (chromosomal abnormalities) (i.e., Down syndrome (trisomy 21), trisomies 13 and 18, Turner syndrome,

5000

$22 q$ deletion, etc.)

New mutations*

3000

30000

Severe congenital malformations $\dagger$ per million births (resulting from all causes of birth defects: generic, unknown, environmental)

Prematurity per million births

40000

Fetal growth retardation per million births

Stillbirths ( $>20$ weeks) per million births

2000-20900

Infertility

$7 \%$ of couples

Modified from ref. 11.

* The mutation rate for many genetic diseases can be calculated; this can be readily performed with dominantly inherited diseases when offspring are born with a dominant genetic disease and neither parent has the disease.

†Congenital malformations have multiple etiologies including a significant proportion that are genetic.

\section{Basic principles of teratology}

To label an environmental agent as teratogenic it is necessary to characterize the dose, route of exposure, and stage of pregnancy when the exposure occurred. A 50-mg dose of thalidomide administered on the 26 th day post conception has a significant risk of malforming the embryo. The same dose taken during the 10 th week of gestation will not result in congenital malformations, and $1 \mathrm{mg}$ of thalidomide taken at any time during pregnancy will have no effect on the developing embryo. X-ray irradiation can be teratogenic; ${ }^{21-23}$ however, if the dose is too low or the X-ray does not directly expose the embryo, there is no increased risk of congenital malformations. ${ }^{3}$ Therefore a list of teratogens indicates only teratogenic potential; evaluation of the dose and time of exposure may indicate that there is no teratogenic risk or that the risk is significant.

Physicians must be careful to carry out a thorough evaluation of the risks faced by a woman exposed to drugs and chemicals during pregnancy, and before alleging that a child's malformations result from exposure to an environmental agent. Clinical teratology and genetics is not emphasized in medical schools and residency education programs. However, clinicians have a multitude of educational aids to assist them in their evaluations; these include consultations with clinical teratologists and geneticists, the medical literature, and the Online Mendelian Inheritance of Man (OMIM) website. ${ }^{24}$

The analysis of human and animal studies on the reproductive effects of environmental agents should be guided by the basic principles of teratology and developmental biology; ${ }^{3}$ these principles are outlined in Table 15.2. ${ }^{25-32}$

\section{The etiology of congenital malformations}

As mentioned earlier, the etiology of congenital malformations can be divided into three categories: unknown, genetic, and environmental (Table 15.3). A significant proportion of congenital malformations of unknown etiology are likely to have an important genetic component. Malformations with an increased recurrent risk such as cleft lip and palate, anencephaly, spina bifida, certain congenital heart diseases, pyloric stenosis, hypospadias, inguinal hernia, talipes equinovarus, and congenital dislocation of the hip fit into the category of multifactorial disease as well as that of polygenic inherited disease. ${ }^{33,34}$ The multifactorial/threshold hypothesis postulates the modulation of a continuum of genetic characteristics by intrinsic and extrinsic (environmental) factors.

A significant percentage of spontaneous errors of development can occur without apparent abnormalities of the genome or environmental influences; these are due to the statistical probability of errors in the developmental process, similar to the concept of spontaneous mutation, and mean that we may never achieve our goal of eliminating birth defects. It is estimated that the majority of all miscarriages occur early in pregnancy, many within the first 3 weeks of development. The World Health Organization estimated that $15 \%$ of all clinically recognizable pregnancies end in spontaneous abortion, 
Table 15.2 Basic scientific principles of teratology.

\begin{tabular}{|c|c|}
\hline Principle & Description \\
\hline $\begin{array}{l}\text { Exposure to teratogens follows a toxicological } \\
\text { dose-response curve }\end{array}$ & $\begin{array}{l}\text { There is a threshold below which no teratogenic effect will be observed. As the } \\
\text { dose of the teratogen is increased, both the severity and frequency of } \\
\text { reproductive effects will increase (Fig. 15.1) }\end{array}$ \\
\hline $\begin{array}{l}\text { The embryonic stage at which exposure occurs will } \\
\text { determine what effects, if any, a teratogen will have }\end{array}$ & $\begin{array}{l}\text { Some teratogens have a broad period of embryonic sensitivity while others have } \\
\text { a very narrow period of sensitivity }\end{array}$ \\
\hline $\begin{array}{l}\text { Most teratogens have a confined group of congenital } \\
\text { malformations referred to as the syndrome of the } \\
\text { agent's effects }\end{array}$ & $\begin{array}{l}\text { Known teratogens may be presumptively implicated by the spectrum of } \\
\text { malformations they produce. It is easier to exclude an agent as a cause of a } \\
\text { birth defect than to definitively prove it was responsible because of the } \\
\text { existence of genocopies of some teratogenic syndromes }\end{array}$ \\
\hline No teratogen can produce every type of malformation & $\begin{array}{l}\text { The presence of certain malformations can eliminate the possibility that a } \\
\text { particular teratogenic agent was responsible because those malformations have } \\
\text { not been demonstrated to be part of the syndrome caused by the teratogen, } \\
\text { or because production of the malformation is not biologically plausible for } \\
\text { that particular alleged teratogen }\end{array}$ \\
\hline
\end{tabular}

Based on concepts from ref. 20 .

Table 15.3 Etiology of human congenital malformations observed during the first year of life.

\begin{tabular}{l}
\hline Suspected cause \\
\hline Unknown \\
Polygenic \\
Multifactorial (gene-environment interactions) \\
Spontaneous errors of development \\
Synergistic interactions of teratogens \\
Genetic \\
Autosomal and sex-linked inherited genetic disease \\
Cytogenetic (chromosomal abnormalities) \\
New mutations \\
Environmental \\
Maternal conditions: alcoholism, diabetes, endocrinopathies, phenylketonuria, smoking and nicotine, starvation, \\
nutritional deficits \\
Infectious agents: rubella, toxoplasmosis, syphilis, herpes simplex, cytomegalovirus, varicella zoster, Venezuelan \\
$\quad$ equine encephalitis, parvovirus B19 \\
Mechanical problems (deformations): amniotic band constrictions, umbilical cord constraint, disparity in uterine \\
$\quad$ size and uterine contents \\
Chemicals, prescription drugs, high-dose ionizing radiation, hyperthermia \\
\hline
\end{tabular}

Modified from ref. 8.

many $(50-60 \%)$ resulting from chromosomal abnormalities. ${ }^{35-38}$ Finally, 3-6\% of offspring are malformed, which represents the background risk for abnormal human development (Table 15.1).

\section{Factors that affect susceptibility to developmental toxicants}

A basic tenet of environmentally produced malformations is that teratogens or a teratogenic milieu have certain character- istics in common and follow certain basic principles. These principles determine the quantitative and qualitative aspects of environmentally produced malformations.

\section{Embryonic stage}

The risk of an exposure to a developmental toxicant resulting in morphological anomalies or intrauterine death depends on the dose and the embryonic or fetal stage at which exposure occurs. The period when an exposure occurs will determine which structures are most susceptible to the deleterious effects 
Table 15.4 Developmental stage sensitivity to thalidomide-induced limb reduction defects in the human.

\begin{tabular}{ll}
\hline $\begin{array}{l}\text { Days from conception } \\
\text { for induction of defects }\end{array}$ & Limb reduction defects \\
\hline $21-26$ & Thumb aplasia \\
$22-23$ & Microtia, deafness \\
$23-34$ & Hip dislocation \\
$24-29$ & Amelia, upper limbs \\
$24-33$ & Phocomelia, upper limbs \\
$25-31$ & Preaxial aplasia, upper limbs \\
$27-31$ & Amelia, lower limbs \\
$28-33$ & Preaxial aplasia, lower limbs; \\
& phocomelia, lower limbs; femoral \\
& hypoplasia; girdle hypoplasia \\
$33-36$ & Triphalangeal thumb \\
\hline
\end{tabular}

Modified from ref. 4.

of the drug or chemical and to what extent the embryo can repair the damage. The period of sensitivity may be narrow or broad, depending on the environmental agent and the malformation in question. Limb defects produced by thalidomide have a very short period of susceptibility ${ }^{4}(2$ weeks; Table 15.4), whereas microcephaly, produced by radiation, has a long period of susceptibility (weeks $8-15$ of pregnancy). ${ }^{3}$

The embryo is most sensitive to the lethal effects of drugs and chemicals during the period of embryonic development, from fertilization through the early postimplantation stage. Surviving embryos have malformation rates that are similar to those of control subjects because significant cell loss or chromosome abnormalities at these stages has a high likelihood of resulting in embryonic death, not because malformations cannot be produced at this stage. Because of the omnipotentiality of early embryonic cells, surviving embryos have a high probability of having malformation rates that are similar to embryos that have not been exposed.

The period of organogenesis (from day 18 through about day 40 post conception in the human) is the period of greatest sensitivity to teratogenic insults and when most gross anatomic malformations can be induced. Most environmentally produced major malformations occur before the 36 th day post conception in the human. The exceptions are malformations of the genito-urinary system, the palate, and the brain, or deformations due to problems of constraint, disruption or destruction.

The fetal period is characterized by histogenesis involving cell growth, differentiation, and migration. Agents that result in cell depletion, vascular disruption, necrosis, specific tissue or organ pathology, physiological decompensation, or severe growth retardation have the potential to cause deleterious effects throughout gestation. The fetus is most sensitive to the induction of mental retardation and microcephaly at the end of the first and the beginning of the second trimester. Other permanent neurological effects can be induced in the second and third trimesters. Effects such as cell depletion or functional abnormalities, not readily apparent at birth, may give rise to changes in behavior or fertility which are only apparent later in life. The last gestational day on which certain malformations may be induced in the human is presented in Table 15.5.

\section{Dose or magnitude of the exposure}

The quantitative correlation between the magnitude of the embryopathic effects and the dose of a drug, chemical, or other agent is referred to as the dose-response relationship. This is extremely important when comparing effects among different species because the use of $\mathrm{mg} / \mathrm{kg}$ doses are, at best, rough approximations. Dose equivalence for drugs and chemicals between humans and other species can be accomplished only by performing pharmacokinetic studies, metabolic studies, and dose-response investigations, whereas ionizing radiation exposures in rads or sieverts ( $\mathrm{Sv}$ ) are similar in most mammalian species. ${ }^{3}$ The response should be interpreted carefully. For example, a substance given in large enough amounts to cause maternal toxicity is also likely to have deleterious effects on the embryo such as death, growth retardation, or retarded development. Also, it is unlikely that progesterone or its synthetic analogues are involved in congenital teratogenesis because the steroid receptors that are necessary for naturally occurring and synthetic progestin action are absent from nonreproductive tissues early in development. ${ }^{7,39-11}$ Several considerations affect the interpretation of dose-response relationships and these are outlined in Table 15.6.

\section{Threshold dose}

The threshold dose is the dose below which the incidence of death, malformation, growth retardation, or functional deficit is not statistically greater than that of control subjects (Fig. 15.1). The threshold level of exposure usually varies between less than one and up to two orders of magnitude below the teratogenic or embryopathic dose for drugs and chemicals that kill or malform one-half of the embryos. An exogenous teratogenic agent, therefore, has a no-effect dose compared with mutagens or carcinogens, which have a stochastic dose-response curve (Table 15.7, Fig. 15.1). The incidence and severity of malformations produced by all exogenous teratogenic agents that have been appropriately studied have exhibited threshold phenomena during organogenesis. ${ }^{\text {? }}$ The threshold concept stems from the principle that manifestations of developmental toxicity occur because the processes of repair and regeneration have been overwhelmed by a particular exposure to a developmental toxicant. It does not predicate that no effect occurs at lower exposures, just that there is no deleterious or irreversible effect. 
Table 15.5 Estimated outcome of pregnancy vs. time from conception.

\begin{tabular}{|c|c|c|c|}
\hline Time from conception & $\begin{array}{l}\text { Percent survival } \\
\text { to term* }\end{array}$ & $\begin{array}{l}\text { Percent loss during } \\
\text { interval* }\end{array}$ & Last time for induction of selected malformations $\dagger$ \\
\hline Pre-implantation & & & - \\
\hline $0-6$ days & 25 & 54.55 & - \\
\hline \multicolumn{4}{|l|}{ Postimplantation } \\
\hline $7-13$ days & 55 & 24.66 & \\
\hline $14-20$ days & 73 & 8.18 & - \\
\hline \multirow[t]{4}{*}{$3-5$ weeks } & 79.5 & 7.56 & 22-23 days: cyclopia, sirenomelia, microtia \\
\hline & & & 26 days: anencephaly \\
\hline & & & 28 days: meningomyelocele \\
\hline & & & 34 days: transposition of great vessels \\
\hline \multirow[t]{3}{*}{$6-9$ weeks } & 90 & 6.52 & 36 days: cleft lip \\
\hline & & & $\begin{array}{l}6 \text { weeks: diaphragmatic hernia, rectal atresia, ventricular septal } \\
\text { defect, syndactyly }\end{array}$ \\
\hline & - & & 9 weeks: cleft palate \\
\hline $10-13$ weeks & 92 & 4.42 & 10 weeks: omphalocele; 12 weeks: hypospadias \\
\hline 14-17 weeks & 96.26 & 1.33 & - \\
\hline $18-21$ weeks & 97.56 & 0.85 & \\
\hline $22-25$ weeks & 98.39 & 0.31 & - \\
\hline $26-29$ weeks & 98.69 & $0.3 \sigma$ & - \\
\hline $30-33$ weeks & 98.98 & 0.30 & - \\
\hline 34-37 weeks & 99.26 & 0.34 & - \\
\hline $38+$ weeks & 99.32 & 0.68 & $38+$ weeks: CNS cell depletion \\
\hline
\end{tabular}

*An estimated $50-70 \%$ of all human miscarriages occur in the first 3 weeks of gestation. ${ }^{36,72}$

†Modified from ref. 60 .

Table 15.6 Considerations that affect the interpretation of dose-response relationships.

\begin{tabular}{|c|c|c|}
\hline Concept & Description & Example \\
\hline Active metabolites & $\begin{array}{l}\text { Metabolites may be the proximate teratogen rather } \\
\text { than the administered drug or chemical }\end{array}$ & $\begin{array}{l}\text { The metabolite phosphoramide mustard and acrolein may } \\
\text { produce abnormal development resulting from the } \\
\text { metabolism of cyclophosphamide }\end{array}$ \\
\hline Duration of exposure & $\begin{array}{l}\text { A chronic exposure to a prescribed drug can } \\
\text { contribute to an increased teratogenic risk }\end{array}$ & $\begin{array}{l}\text { Anticonvulsant therapy; in contrast an acute exposure to the } \\
\text { same drug may present little or no teratogenic risk }\end{array}$ \\
\hline Fat solubility & $\begin{array}{l}\text { Fat-soluble substances can produce fetal } \\
\text { malformations for an extended period after the } \\
\text { last ingestion or exposure because they have an } \\
\text { unusually long half-life }\end{array}$ & $\begin{array}{l}\text { Polychlorinated biphenyls (PCBs). Etretinate may present a } \\
\text { similar risk but the data are not conclusive }\end{array}$ \\
\hline
\end{tabular}

\section{Pharmacokinetics and metabolism of the drug or chemical}

Physiological alterations during pregnancy as well as the bioconversion of compounds can significantly influence the teratogenic effects of drugs and chemicals by affecting absorption, body distribution, the active form(s), and excretion of the compound. Tables 15.8 and 15.9 outline the pregnancyrelated physiological alterations in the mother and fetus, respectively, that affect the pharmacokinetics of drugs. ${ }^{42-44}$
Although other organs, including the placenta, can be involved in the metabolism of drugs or chemicals, the major site of bioconversion of chemicals in vivo is likely to be the maternal liver. Placental P450-dependent monooxygenation of xenobiotics will occur at low rates unless induced by compounds such as those found in tobacco smoke. ${ }^{45}$ However, the rodent embryo and yolk sac have been shown to possess functional p450-oxidative isozymes capable of converting proteratogens to active metabolites during early organogenesis. ${ }^{46}$ In addition, P450-independent bioactivation has been 


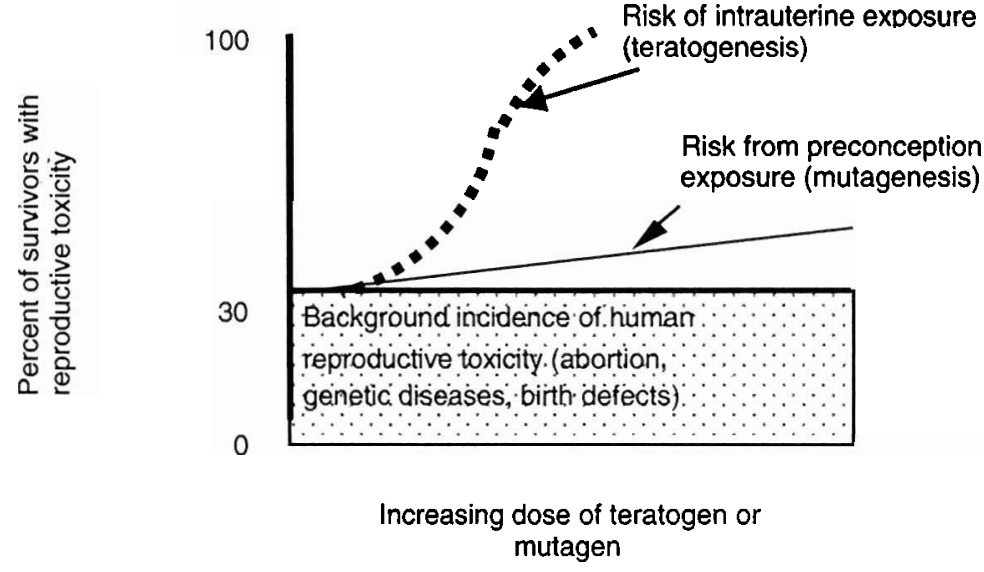

Figure 15.1 Dose-response relationship of reproductive toxins comparing preconception and postconception risks.

Table 15.7 Stochastic and threshold dose-response relationships of diseases produced by environmental agents.

\begin{tabular}{|c|c|c|c|c|c|}
\hline Relationship & Pathology & Site & Diseases & Risk & Definition \\
\hline $\begin{array}{l}\text { Stochastic } \\
\text { phenomena }\end{array}$ & $\begin{array}{l}\text { Damage to a single } \\
\text { cell may result in } \\
\text { disease }\end{array}$ & DNA & Cancer, mutation & $\begin{array}{l}\text { Some risk exists at all } \\
\text { dosages; at low } \\
\text { exposures the risk is } \\
\text { below the } \\
\text { spontaneous risk }\end{array}$ & $\begin{array}{l}\text { The incidence of the } \\
\text { disease increases with } \\
\text { the dose but the severity } \\
\text { and nature of the } \\
\text { disease remain the same }\end{array}$ \\
\hline $\begin{array}{l}\text { Threshold } \\
\text { phenomena }\end{array}$ & Multicellular injury & $\begin{array}{l}\text { High variation in } \\
\text { etiology, affecting } \\
\text { many cell and } \\
\text { organ processes }\end{array}$ & $\begin{array}{l}\text { Malformation, } \\
\text { growth retardation, } \\
\text { death, chemical } \\
\text { toxicity, etc. }\end{array}$ & $\begin{array}{l}\text { No increased risk } \\
\text { below the threshold } \\
\text { dose }\end{array}$ & $\begin{array}{l}\text { Both the severity and } \\
\text { incidence of the disease } \\
\text { increase with dose }\end{array}$ \\
\hline
\end{tabular}

Modified from ref. 73.

Table 15.8 Pregnancy-related physiological alterations in the mother that affect the pharmacokinetics of drugs.

\begin{tabular}{|c|c|}
\hline Alteration & Effect on drug pharmacokinetics \\
\hline $\begin{array}{l}\text { Decreased gastrointestinal motility; increased intestinal } \\
\text { transit time }\end{array}$ & $\begin{array}{l}\text { Results in delayed absorption of drugs in the small intestine owing to increased } \\
\text { stomach retention and enhanced absorption of slowly absorbed drugs }\end{array}$ \\
\hline Decreased plasma albumin & Alters the kinetics of compounds normally bound to albumin \\
\hline Renal elimination & Generally increased but is influenced by body position later in pregnancy \\
\hline Increased plasma and extracellular fluid volumes & Affects concentration-dependent transfer of compounds \\
\hline Inhibition of metabolic inactivation in the maternal liver & Increases half-life of drug in plasma \\
\hline Variation in uterine blood flow & May afect transfer across the placenta (although little is known concerning this) \\
\hline
\end{tabular}

Based on concepts from refs $42-44$. 
Table 15.9 Pregnancy-related physiological alterations in the fetus that may affect the pharmacokinetics of drugs.

\begin{tabular}{ll}
\hline Alteration & Effect on drug pharmacokinetics \\
\hline $\begin{array}{l}\text { Amount and distribution of fat } \\
\text { Lower plasma protein concentrations }\end{array}$ & $\begin{array}{l}\text { Affects distribution of lipid-soluble drugs and chemicals } \\
\text { Results in a higher concentration of unbound drug in the fetal circulation } \\
\text { Functional development of pharmacological } \\
\text { receptors }\end{array}$ \\
$\begin{array}{l}\text { Likely to proceed at different rates in the various tissues of the developing fetus } \\
\text { Extent of amniotic fluid swallowing }\end{array}$ & $\begin{array}{l}\text { Drugs that are excreted by the fetal kidneys may be recycled through the fetus via swallowing } \\
\text { of amniotic fluid }\end{array}$ \\
\hline
\end{tabular}

Based on concepts from refs $42-44$.

suggested; for example, there is strong evidence that the rat embryo can reductively convert niridazole to an embryotoxic metabolite. ${ }^{47}$

Bioconversion of xenobiotics has been shown to be important in their teratogenic activity. There is strong evidence that the reactive metabolites of cyclophosphamide, 2 -acetylaminofluorene, and nitroheterocycles (niridazole) are the proximate teratogens. ${ }^{48}$ There is also experimental evidence suggesting that other chemicals undergo conversion to intermediates that have deleterious effects on embryonic development, for example, phenytoin, procarbazine, rifampicin, diethylstilbestrol, some benzhydrylpiperazine antihistamines, adriamycin, testosterone, benzo(a)pyrene, methoxyethanol, caffeine, and paraquat. ${ }^{45,48}$

$\mathrm{Juchau}^{48}$ has defined several experimental criteria to suggest that a suspected metabolite is responsible for the in vivo teratogenic effects of a chemical or drug (Table 15.10). These criteria may explain why there are marked qualitative and quantitative differences in the species response to a teratogenic agent.

\section{Placental transport}

It has been suggested that the placental barrier is protective and that harmful substances do not reach the embryo; however, it is now clear that there is no "placental barrier" per se. The package inserts on many drugs state that "this drug crosses the placental barrier" 6 and the uninitiated may infer from this statement that this characteristic of a drug is both unusual and hazardous. However, most drugs and chemicals cross the placenta, and only selected proteins, whose actions are species specific, will cross the placental barrier in one species but not another.

The role that the placenta plays in drug pharmacokinetics has been reviewed by Juchau and Rettie ${ }^{45}$ and involves: (1) transport; (2) the presence of receptor sites for a number of endogenous and xenobiotic compounds ( $\beta$-adrenergic agents, glucocorticoids, epidermal growth factor, IgG-Fc, insulin, lowdensity lipoproteins, opiates, somatomedin, testosterone, transcobalamin II, transferrin, folate, retinoid); ${ }^{49}$ and (3) the bioconversion of xenobiotics.

The factors which determine the ability of a drug or chemical to cross the placenta and reach the embryo include molecular weight, lipid affinity or solubility, polarity or degree of
Table 15.10 Criteria to suggest that a suspected metabolite is responsible for the in vivo teratogenic effects of a drug or chemical.

The chemical must be convertible to the intermediate

The intermediate must be found in, or have access to, the tissue(s) affected

The embryotoxic effect should increase with the concentration of the metabolite

Inhibiting the conversion should reduce the embryotoxic effect of the agent

Promoting the conversion should increase the embryotoxicity of the agent

Inhibiting or promoting conversion should not alter the target tissues

Inhibiting the conversion should increase the embryotoxicity of the agent

Based on concepts from ref. 48.

ionization, protein binding, and receptor mediation. Compounds with a low molecular weight and lipid affinity, nonpolarity, and without protein-binding properties will cross the placenta rapidly and with ease. For example, ethyl alcohol reaches the embryo rapidly and in concentrations equal to or greater than the level in the mother. High-molecular-weight compounds like heparin ( 20000 daltons) do not cross the placenta readily and, therefore, during pregnancy, heparin is used instead of warfarin-like compounds for the treatment of hypercoagulation conditions. Rose Bengal does not cross the placenta at all. In general, compounds with molecular weights of 1000 daltons or more do not readily cross the placenta, whereas those less than 600 daltons usually do; most drugs are $250-400$ daltons and do cross the placenta. ${ }^{50}$

\section{Genetic differences}

The genetic constitution of an organism is an important factor in the susceptibility of a species to a drug or chemical. More than 30 disorders of increased sensitivity to drug toxicity or effects in the human result from an inherited trait. ${ }^{51}$ Maternal and fetal genotypes determine the types of bioconversion route, the rate at which bioconversions take place, and the extent to which a compound is metabolized. 


\section{Environmental agents resulting in reproductive toxicity following exposure during pregnancy}

Table 15.11 lists environmental agents that have resulted in reproductive toxicity and/or congenital malformations in humans. The list should not be used in isolation because many other parameters must be considered when analyzing reproductive risks in individual patients. Many of these agents represent a very small risk while others may represent substantial risks; the risks will vary with the magnitude, timing, and length of exposure. Further information can be obtained from more extensive reviews or summary articles. Table 15.12 lists agents that have had concerns raised about their reproductive effects but which, after a careful and complete evaluation, have not been found to represent an increased reproductive risk. ${ }^{41,52-55}$ References for the environmental agents can be found in review articles and texts on teratogenesis. ${ }^{13,18,24,38,51,56-61}$

\section{Interpretation of animal study data for assessment of reproductive risks in humans}

As human studies are expensive and take years to complete, scientists have investigated the issue of whether appropriate animal models can be used to evaluate the reproductive and toxicological risks of environmental agents in humans (teratogenesis, growth retardation, pregnancy loss, stillbirth, and infertility).

Whole animal teratology studies are helpful in raising concerns about the reproductive effects of drugs and chemicals; however, negative animal studies do not guarantee that these agents are free from reproductive effects in humans. There are examples in which drug testing was negative in animals (rat and mouse), but was teratogenic in the human (thalidomide). ${ }^{27}$ Similarly, there are examples in which a drug was teratogenic in an animal model but not in humans (diflunisal). Therefore, while chemicals and drugs can be evaluated for their toxic potential by utilizing in vivo animal studies and in vitro systems, it should be recognized that these testing procedures are only one component in the process of evaluating the potential toxic risk of drugs and chemicals. Wellperformed epidemiology studies still represent the best methodology for determining the risks and effects of environmental toxicants on humans. Indeed, most human teratogens have been discovered by alert physicians or during epidemiology studies, not animal studies. ${ }^{62}$ In vitro studies play an even less important role, although they are helpful in describing the cellular or tissue-specific effects of drugs and chemicals.

One useful aspect of animal studies is in corroborating findings reported in epidemiological studies. Attempts at risk assessment can be made by utilizing toxicokinetic data that have been obtained in an animal model, and exposure levels of the alleged toxicant and its metabolites that have been determined in humans. Studies to elucidate whether the mechanism of action of a drug or chemical in the animal model is the same as that in humans would further add to the toxicologist's ability to estimate human risks. This is not a simple process and explains why good-quality epidemiological studies are so valuable in determining human risks and toxicity.

Clinicians are given little training in medical school and during residency training on how to interpret animal toxicology studies. This is probably more true of reproductive

Table 15.11 Proven human teratogens or embryotoxins: drugs, chemicals, milieu, and physical agents that have resulted in human congenital malformations.
Reproductive toxin
Alleged effects

Aminopterin, methotrexate

Androgens

Angiotensin-converting enzyme

(ACE) inhibitors

Antituberculous therapy

Caffeine

Chorionic villus sampling (CVS)

Cobalt in hematemic multivitamins

Cocaine

Corticosteroids

Coumarin derivative
Growth retardation, microcephaly, meningomyelocele mental retardation, hydrocephalus, and cleft palate Along with high doses of some male-derived progestins, can cause masculinization of the developing fetus Fetal hypotension syndrome in second and third trimester resulting in fetal kidney hypoperfusion and anuria, oligohydramnios, pulmonary hypoplasia, and cranial bone hypoplasia. No effect in the first trimester

The drugs isoniazid (INH) and paraaminosalicylic acid (PAS) have an increased risk for some CNS abnormalities

Moderate exposure not associated with birth defects; high exposures associated with an increased risk of abortion but data are inconsistent

Vascular disruptive malformations, i.e., limb reduction defects

Fetal goiter

Very low incidence of vascular disruptive malformations, pregnancy loss

High exposures administered systemically have a low risk for cleft palate in some epidemiological studies; however, this is not a consistent finding

Exposure during early pregnancy can result in nasal hypoplasia, stippling of secondary epiphysis, and intrauterine growth retardation. Exposure in late pregnancy can result in CNS malformations as a result of bleeding 
Table 15.11 Continued.

\author{
Cyclophosphamide and other \\ chemotherapeutic and \\ immunosuppressive agents, \\ e.g., cyclosporine, leflunomide \\ Diethylstilbestrol
}

Ethyl alcohol

Ionizing radiation

Insulin shock therapy

Lithium therapy

Minoxidil

Methimazole

Methylene blue intraamniotic instillation

Misoprostol

Penicillamine (D-penicillamine)

Progestin therapy

Propylthiouracil

Radioactive isotopes

Retinoids, systemic

Retinoids, topical

Streptomycin

Sulfa drug and vitamin $\mathrm{K}$

Tetracycline

Thalidomide

Trimethoprim

Vitamin A (retinol)

Vitamin $D^{*}$

Warfarin (coumarin)

Anticonvulsants

Carbamazepine
Many chemotherapeutic agents used to treat cancer have a theoretical risk of producing fetal malformations, as most of these drugs are teratogenic in animals; however, the clinical data are not consistent. Many have not been shown to be teratogenic but the numbers of cases in the studies are small; caution is the byword

Genital abnormalities, adenosis, and clear cell adenocarcinoma of the vagina in adolescents. The risk of adenosis can be quite high; the risk of adenocarcinoma is 1:1000 to $1: 10000$

Fetal alcohol syndrome (microcephaly, mental retardation, growth retardation, typical facial dysmorphogenesis, abnormal ears, and small palpebral fissures)

A threshold greater than 20 rad $(0.2 \mathrm{~Gy})$ can increase the risk of some fetal effects such as micocephaly or growth retardation. The threshold for mental retardation is higher

Microcephaly and mental retardation

Chronic use for the treatment of manic depressive illness has an increased risk for Ebstein's anomaly and other malformations, but the risk appears to be very low

Hirsutism in newborns (led to the discovery of the hair growth-promoting properties of minoxidil)

Aplasia cutis has been reported*

Fetal intestinal atresia, hemolytic anemia, and jaundice in the neonatal period. This procedure is no longer utilized to identify one twin

Low incidence of vascular disruptive phenomenon, such as limb reduction defects and Mobius syndrome, has been reported in pregnancies in which this drug was used to induce an abortion

This drug results in the physical effects referred to as lathyrism, the results of poisoning by the seeds of the genus Lathyrus. It causes collagen disruption, cutis laxa, and hyperflexibility of joints. The condition appears to be reversible and the risk is low

Very high doses of androgen hormone-derived progestins can produce masculinization. Many drugs with progestational activity do not have masculinizing potential. None of these drugs has the potential for producing congenital malformations

Along with other antithyroid medications can result in an infant born with a goiter

Tissue- and organ-specific damage is dependent on the radioisotope element and distribution, i.e., high doses of ${ }^{131} \mathrm{I}$ administered to a pregnant woman can cause fefal thyroid hypoplasia after the 8th week of development

Systemic retinoic acid, isotretinoin, and etretinate can result in an increased risk of CNS, cardio-aortic, ear, and clefting defects, microtia, anotia, thymic aplasia and other branchial arch and aortic arch abnormalities, and certain congenital heart malformations

This is very unlikely to have teratogenic potential because teratogenic serum levels are not achieved from topical exposure

Streptomycin and a group of ototoxic drugs can affect the eighth nerve and interfere with hearing; it is a relatively low-risk phenomenon. Children are even less sensitive to the ototoxic effects of these drugs than adults

Hemolysis in some subpopulations of fetuses

Bone and teeth staining

Increased incidence of deafness, anotia, preaxial limb reduction defects, phocomelia, ventricular septal defects, and GI atresias during susceptible period from the 22 nd to the 36 th day post conception

This drug was frequently used to treat urinary tract infections and has been linked to an increased incidence of neural tube defects. The risk is not high, but it is biologically plausible because of the drug's lowering effect on folic acid levels. This has also resulted in neurological symptoms in adults taking this drug

Very high doses of vitamin A have been reported to produce the same malformations as those reported for the retinoids. Dosages sufficient to produce birth defects would have to be in excess of 25000 to 50000 units per day

Large doses given in vitamin $\mathrm{D}$ prophylaxis are possibly involved in the etiology of supravalvular aortic stenosis, elfin facies, and mental retardation

Exposure during early pregnancy can result in nasal hypoplasia, stippling of secondary epiphysis, and intrauterine growth retardation. Exposure in late pregnancy can result in CNS malformations as a result of bleeding

Used in the reatment of convulsive disorders; increases the risk of facial dysmorphology 
Table 15.11 Continued.

Diphenylhydantoin

Trimethadione and paramethadione

Valproic acid

\section{Chemicals}

Carbon monoxide poisoning ${ }^{*}$

Gasoline addiction embryopathy

Lead

Methyl mercury

Polychlorinated biphenyls

Toluene addiction embryopathy

Embryonic and fetal infections

Cytomegalovirus

Herpes simplex virus

Human immunodeficiency

virus (HIV)

Parvovirus B19 infection

Rubella virus

Syphilis

\section{Toxoplasmosis}

Varicella zoster virus

Venezuelan equine encephalitis

Maternal disease states

Corticosteroid-secreting endocrinopathy

Iodine deficiency

Intrauterine problems of constraint and vascular disruption

Maternal androgen endocrinopathy (adrenal tumors)

Maternal diabetes

Folic acid insufficiency in the mother

Maternal phenylketonuria

Maternal starvation

Tobacco smoking

Zinc deficiency"
'Used in the treatment of convulsive disorders; increases the risk of fetal hydantoin syndrome, consisting of facial dysmorphology, cleft palate, ventricular septal defect (VSD), and growth and mental retardation

Used in the treatment of convulsive disorders; increases the risk of characteristic facial dysmorphology, mental retardation, V-shaped eyebrows, low-set ears with anteriorly folded helix, high-arched palate, irregular teeth, CNS anomalies, and severe developmental delay

Used in the treatment of convulsive disorders; increases the risk of spina bifida, facial dysmorphology, and autism

CNS damage has been reported with very high exposures, but the risk appears to be low

Facial dysmorphology, mental retardation

Very high exposures can cause pregnancy loss; intrauterine teratogenesis is not established

Causes Minamata disease consisting of cerebral palsy, microcephaly, mental retardation, blindness, and cerebellum hypoplasia. Endemics have occurred from adulteration of wheat with mercury-containing chemicals that are used to prevent grain spoilage. Present environmental levels of mercury are unlikely to represent a teratogenic risk, but reducing or limiting the consumption of carnivorous fish has been suggested in order not to exceed the Environmental Protection Agency's (EPA's) maximum permissible exposure (MPE), which is far below the toxic effects of mercury

Poisoning has occurred from adulteration of food products (cola-colored babies, CNS effects, pigmentation of gums, nails, teeth and groin, hypoplastic deformed nails, intrauterine growth retardation, abnormal skull calcification). The threshold exposure has not been determined, but it is unlikely to be teratogenic at the present environmental exposures

Facial dysmorphology, mental retardation

Retinopathy, CNS calcification, microcephaly, mental retardation

Fetal infection, liver disease, death

Perinatal HIV infection

Stillbirth, hydrops

Deafness, congenital heart disease, microcephaly, cataracts, mental retardation

Maculopapular rash, hepatosplenomegaly, deformed nails, osteochondritis at joints of extremities, congenital neurosyphilis, abnormal epiphyses, chorioretinitis

Hydrocephaly, microphthalmia, chorioretinitis, mental retardation

Skin and muscle defects, intrauterine growth retardation, limb reduction defects, CNS damage (very low increased risk)

Hydranencephaly, microphthalmia, CNS destructive lesions, luxation of hip

Mothers with Cushing's disease can have infants with hyperadrenocortism, but anatomical malformations do not appear to be increased

Iodine deficiency can result in embryonic goiter and mental retardation

Defects such as club feet, limb reduction, aplasia cutis, cranial asymmetry, external ear malformations, midline closure defects, cleft palate and muscle aplasia, cleft lip, omphalocele, and encephalocele. More common in multiple-birth pregnancies, pregnancies with anatomical defects of the uterus, placental emboli, and amniotic bands

Masculinization

Caudal and femoral hypoplasia, transposition of great vessels Increased incidence of neural tube defects (NTDs)

Abortion, microcephaly, and mental retardation. Very high risk in untreated patients Intrauterine growth retardation, abortion, NTDs Abortion, intrauterine growth retardation, and stillbirth NTDs

\footnotetext{
${ }^{*}$ Controversial.
} 
Table 15.12 Agents erroneously alleged to have caused human malformations.

Agent

Alleged effect

- Doxylamine succinate (Bendectin) Diagnostic ultrasonography Electromagnetic fields (EMF) Progestational drugs

Trichloroethylene (TCE)
Alleged to cause numerous types of birth defects including limb reduction defects and heart malformations No significant hyperthermia, therefore no reproductive effects

Alleged to cause abortion, cancer, and birth defects

Alleged to cause numerous types of congenital birth defects, including limb reduction defects and heart malformations

Alleged to cause cardiac defects toxicology studies than of any other area of animal testing. For physicians the best source of information concerning animal testing comes from the drug package insert or the Physicians' Desk Reference (PDR). ${ }^{63}$ The PDR utilizes the Food and Drug Administration's (FDA's) classification of reproductive risks (caregories A, B, C, D, and X), which is partly based on animal testing. Category $\mathrm{A}$ includes drugs that present no risk of reproductive effects. Category $B, C$ and $D$ drugs show increasing risks and category $\mathrm{X}$ includes drugs such as methotrexate, isotretinoin (Acutane), or thalidomide that should not be used in pregnant women or women of reproductive age who are not taking contraceptives. However, these categories are often more misleading than helpful. Teratologists, obstetricians, and other clinicians who counsel pregnant women have been very critical of the FDA's classification ${ }^{6}$ because it ignores the basic principles of teratology ${ }^{3}$ and the importance of modern pharmacokinetics in evaluating animal studies. ${ }^{29}$ In 1990, an article was published which indicated that of the 200 most frequently prescribed drugs, none represented a significant teratogenic risk. ${ }^{64}$ However, only a small proportion of these drugs was placed in category A by the FDA, the most important reason being the misapplication of animal testing results. When a new drug is marketed or a new environmental toxicant is discovered, however, often the only information that is available are the animal data.

\section{Evaluating animal studies to determine the potential risk in humans}

When utilizing animal data to assess the potential risk of a drug or chemical exposure in humans, it is important to critically evaluate the studies using the basic principles of teratology guidelines (Table 15.2). As discussed previously, one of the most critical factors for consideration is the dose or magnitude of the exposure, and the concept of the threshold-dose effect for reproductive toxicants. A major shortcoming in many studies is the use of weight $(\mathrm{mg} / \mathrm{kg})$ as a measure of dose, as dose comparisons based on $\mathrm{mg} / \mathrm{kg}$ doses are, at best, rough approximations. Instead, testing in animals could be improved if drugs and chemicals were administered to achieve pharmacokinetically equivalent serum levels in the animal and human. Dose equivalence between species can be accomplished only by performing pharmacokinetic studies, metabolic studies, and dose-response investigations in the human and the species being studied. Dose equivalence must also be determined for the drug-specific effects at the cellular level, to account for species differences in the molecular targets of chemicals or drugs. An excellent example of the importance of the use of pharmacological, rather than weight-based, dose equivalence in interpreting animal study data is illustrated by animal and epidemiological studies performed on leflunomide. ${ }^{32}$

Leflunomide is a relatively new drug (1998) which is used to treat rheumatoid arthritis. It contains a warning for reproductive effects (teratogenesis) and has been placed in category $\mathrm{X}$. This classification was based on animal studies as there were no human data available at the time of marketing.

Leflunomide is a novel isoxazole immunomodulatory agent that has antiproliferative activity. It inhibits mitogenstimulated proliferation of human peripheral blood mononuclear cells (PBMCs) in a dose-dependent fashion. It has been demonstrated that the active metabolite binds to, and is a potent inhibitor of, dihydroorotate dehydrogenase (DHODH), an enzyme important for DNA synthesis in the de novo pyrimidine synthesis pathway. Together, these data suggest that at serum concentrations achievable in patients, leflunomide inhibits de novo pyrimidine synthesis in activated lymphocytes and other rapidly dividing cell populations, resulting in reversible cell cycle arrest.

In oral embryotoxicity and teratogenicity studies in rats and rabbits, leflunomide was embryotoxic (growth retarding, embryolethal, and teratogenic). The no-effect level for embryotoxicity and teratogenicity in rats and rabbits was $1 \mathrm{mg} / \mathrm{kg}$ body weight, which resulted in serum levels of 3.7 and $4.1 \mu \mathrm{g} / \mathrm{mL}$ respectively. In patients being treated with leflunomide, the active metabolite (the pyrimidine antagonist), is maintained at a blood level of $40 \mu \mathrm{g} / \mathrm{mL}$. The decision to label leflunomide as having a teratogenic risk was based on the fact that the human serum level was in the range of the teratogenic blood level in the animal models, and, therefore, the initial labeling was an appropriate precaution to prevent birth defects.

After 4 years of treating rheumatoid arthritic patients with leflunomide there was no indication of an increase in teratogenesis in a very small group of pregnant patients who continued their pregnancy to term. The animal data were, therefore, reanalyzed as follows (referred to as the method of action (MOA) approach). The most likely mechanism of leflunomide teratogenicity is the suppression of DNA 
synthesis and cell proliferation by the inhibition of pyrimidine synthesis. This is based on the assumption that, at the same serum levels of the active metabolite of leflunomide, suppression of DNA synthesis, pyrimidine synthesis, and cell proliferation is equal in the rat, rabbit, and human. There would then be concurrence and the risks would be determined to be identical in all three species; this was the basis of the X-category labeling. However, in vitro studies on the active metabolite of leflunomide revealed that the rat was 40 and 328 times more sensitive to the suppression of DHODH and cell proliferation, respectively, than the human. ${ }^{32}$ This means that if enzyme suppression or antiproliferative activity is the mechanism (MOA) of teratogenicity in the rat, then the clinical use of leflunomide in pregnant women would probably not be teratogenic. It is important that this drug is subjected to ongoing epidemiological surveillance to confirm these findings. This is an example of how modern pharmacokinetic studies can improve risk assessment, making it easier to understand the epidemiological studies.

\section{Examples of in vivo animal studies}

In the past 2 years, many excellent in vivo animal studies have been carried out. Two particular studies demonstrate the importance, differences, and the usefulness of animal studies as well as the difficulties inherent in drawing inferences from animal studies to describe human risk. Dam and coauthors ${ }^{65}$ used an in vivo animal model to study the effect of chlorpyrifos (CPF), an organophosphate insecticide whose domestic use has been curtailed in the USA because of concerns about its neurotoxicity, on gene expression. Newborn animals were injected subcutaneously with one of two different doses of $\mathrm{CPF}$ on postnatal days $1-4$ or 11-14. Studies of the forebrain using molecular biological techniques revealed a significant elevation in one protein that persisted for 5 days after cessation of the exposure regimen. This is an interesting study; however, the results are of little use in determining the human risks of $\mathrm{CPF}$ for the following reasons:

$1 \mathrm{CPF}$ exposure in humans does not occur via subcutaneous injection but by ingestion or skin absorption of contaminated food or water.

2 The serum concentration of CPF was not determined for the two different exposures used.

3 There was no discussion of the range of levels of CPF that have occurred in human populations.

4 The threshold dose and the no-observed adverse effect level (NOAEL) were not determined.

5 The authors performed toxicogenomics without toxicokinetics.

In contrast, the in vivo study by Tyl and coauthors ${ }^{66}$ on the reproductive toxicity of dietary bisphenol in rats is considered to be a modern, animal toxicology study for the following reasons:

1 The bisphenol was placed in the diet ad libitum.
2 There were seven exposure groups.

3 The exposures were listed in ppm and $\mathrm{mg} / \mathrm{kg}$.

4 The range of exposures used was very large: 0.001$500 \mathrm{mg} / \mathrm{kg}$ or a 500000 -fold range.

5 The following were not affected at any of the lower exposures although some effects were observed in the $500 \mathrm{mg} / \mathrm{kg}$ group: mating, fertility, gestational indices, ovarian primordial follicle counts, estrous cyclicity, precoital interval, gestational length, offspring sex ratios, postnatal survival, nipple/areolae retention in pre-weanling males, epididymal sperm number, motility, and morphology, daily sperm production, and efficiency of production

6 The adult NOAEL was $5 \mathrm{mg} / \mathrm{kg} /$ day and the reproductive NOAEL was $50 \mathrm{mg} / \mathrm{kg} /$ day. There was a reduction in total body weight and some reduction in organ weight at the higher exposures.

To perform a risk analysis for bisphenol in the human population, some additional information is required that was not reported in this study but which is available in other studies. Yamada and coauthors ${ }^{67}$ obtained bisphenol exposure data in humans from the mother and amniotic fluid. The average concentration of bisphenol was $0.32 \mathrm{ng} / \mathrm{mL}$ of serum, with a range of $0.0-1.6 \mathrm{ng} / \mathrm{mL}$, levels which appear to be far below the threshold exposure determined by Tyl and coauthors. However, Tyl and coauthors did not obtain the same pharmacokinetic data in the rat that Yamada and coauthors reported in the human, and therefore the serum concentration of bisphenol in the rat at the threshold exposure is not known. Furthermore, it is not known whether the metabolism and effects of bisphenol are similar in the human and the rat.

These studies ${ }^{66,67}$ on the risk analysis for bisphenol in the human population indicate the difficulties that can be faced in achieving an accurate and complete interpretation of the data. Combining such studies may appear to be a rare occurrence in the field of risk analysis; fortunately, however, it is occurring more often. ${ }^{68}$

\section{In vitro testing}

In vitro tests can be utilized for preliminary screening procedures, and to study the mechanisms of teratogenesis and embryogenesis. However, in vitro studies will never be able to predict human teratogenic risks at particular exposures without additional data obtained from whole animal and epidemiological studies. ${ }^{25,29,31,60}$ In spite of the advances in in vitro and in vivo testing for teratogenicity, human epidemiological surveillance by various methodologies is, and will continue to be, our most powerful tool for discovering human reproductive toxins and teratogens. It may be difficult for experimental teratologists to accept the fact that alert physicians and scientists have been the most prominent contributors to the discovery of the environmental causes of birth defects. ${ }^{26}$ 


\section{The role of the physician in counseling families regarding the etiology of a child's congenital malformation}

The clinician must be cognizant of the fact that many patients believe that most congenital malformations are caused by a drug or medication taken during pregnancy. Counseling patients about reproductive risks requires a significant degree of knowledge and skill. Physicians must also realize that erroneous counseling by inexperienced health professionals may result in nonmeritorious litigation. ${ }^{2}$

Unfortunately, it has sometimes been assumed that if a drug or chemical causes birth defects in an animal model or in vitro system at a high dose, then it has the potential for producing birth defects at any dose. ${ }^{27,29}$ This may be reinforced by the fact that many teratology studies reported in the literature investigate the effects of several doses but do not determine the no-effect dose.

Ignoring the basic tenets of teratology appears to occur most commonly in the evaluation of environmental toxic exposures when the exposure is very low or unknown, and the agent has been reported to be teratogenic at a very high dose or a maternally toxic dose. In most instances, the actual population exposure is orders of magnitude below the threshold dose, the doses that were used in animal studies, or those received during toxic exposures in the population. This has been the case with 2,4,5-trichlorophenoxyacetic acid $(2,4,5-\mathrm{T})$, polychlorinated biphenyls (PCBs), lead, cadmium, arsenic, pesticides, herbicides, veterinary hormones, and industrial exposures.

Unfortunately, there are examples where environmental disasters have been responsible for birth defects or pregnancy loss in exposed populations (methyl mercury in Japan, PCBs in the Far East, organic mercury in the Middle East, and lead poisoning in the nineteenth and early twentieth centuries) and examples where teratogenic drugs have been inadvertently introduced (Table 15.11). Therefore, it is not possible to determine whether a chemical or drug is safe or hazardous unless the magnitude of the exposure is known.

\section{Scholarly evaluation}

The physician should respond to a parent's query into the cause of a child's birth defect using the same professional and methodical approach that would be used in a differential diagnosis for any clinical problem. Physicians have a protocol for evaluating complex clinical problems, for example, "fever of unknown origin," "failure to thrive," "congestive heart failure," or "respiratory distress." If a mother of a malformed infant had some type of exposure during pregnancy, for example, medication or a diagnostic radiological examination, the consulting physician should not support or suggest the possibility of a causal relationship before performing a com- plete evaluation. This is also true if a pregnant woman is exposed to a drug, chemical, or physical agent. As mentioned previously, only a small percentage of birth defects result from exposure to prescribed drugs, chemicals, and physical agents ${ }^{12,64}$ (Table 15.3). Even when the drug is listed as a teratogen, to exert a teratogenic effect it has to be administered during the sensitive period of development for that drug, and above the threshold dose. Furthermore, the malformations in a child should be the same as the malformations in the teratogenic syndrome produced by that particular drug. It should be emphasized that in a recent analysis of the 200 most prescribed drugs in the USA, none were found to have measurable teratogenic potential. ${ }^{64}$

After a complete examination of the child and a review of the genetic and teratology medical literature, the clinician must decide whether the child's malformations are genetic or result from exposure to an environmental toxin or agent. It may not be possible to definitively or presumptively conclude the etiology of the child's birth defects. This information must then be conveyed to the parient in an objective and compassionate manner. A similar situation exists if a pregnant woman has been exposed to a drug, chemical, or physical agent, as the mother will want to know the risk of the exposure to her unborn child. A formal approach is recommended to determine whether a particular environmental drug, chemical or physical agent is a reproductive toxicant; this should include, where possible, data obtained from a number of investigative approaches (Table 15.13 ${ }^{20}$ ) including: (1) epidemiological studies, ${ }^{25,26}$ (2) secular trend or ecological trend analysis, (3) animal reproductive studies, ${ }^{27-31}$ (4) dose-response relationships and pharmacokinetic, toxicokinetic, pharmacodynamic, and toxicodynamic studies comparing human and animal metabolism, (5) MOA studies that pertain specifically to the agent and include receptor affinity, cytotoxicity, genotoxicity, organ toxicity, neurotoxicity, etc., ${ }^{25.2 K .301,32}$ (6) biological plausibility.

Some typical analyses of the reproductive risks of doxylamine succinate (Bendectin), sex steroids, diagnostic ultrasound, and electromagnetic fields demonstrate the usefulness of an organized approach to determine whether an environmental agent has been demonstrated to be a reproductive toxin. $^{41,52-55,69}$

\section{Clinical evaluation}

There are many articles and books that can assist the physician with the evaluation of the medical literature and the clinical evaluation of the patient, ${ }^{13,18,24,38,51,56-61}$ although training programs do not usually prepare generalists to perform sophisticated genetic or teratology counseling. In addition to the usual history and physical evaluation, the physician has to obtain information about the nature, magnitude, and timing of the exposure. The physical examination should include descriptive and quantitative information about the physical 
Table 15.13 Proof of developmental toxicity in humans.

\section{Epidemiological studies}

Controlled epidemiological studies consistently demonstrate an increased incidence of a particular spectrum of embryonic and/or fetal effects in exposed human populations

\section{Secular trend data}

Secular trends demonstrate a positive relationship between the changing exposures to a common environmental agent in human populations and the incidence of a particular embryonic and/or fetal effect

\section{Animal developmental toxicity studies}

An animal model that mimics the human developmental effect at clinically comparable exposures can be developed. Because mimicry may not occur in all animal species, animal models are more likely to be developed once there is good evidence for the embryotoxic effects reported in the human. Developmental toxicity studies in animals are indicative of a potential hazard in general rather than the potential for a specific adverse effect on the fetus when there are no human data on which to base the animal experiments

Dose-response relationship (pharmacokinetics and toxicokinetics)

Developmental toxicity in the human increases with dose (exposure), and the developmental toxicity in animals occurs at a dose that is pharmacokinetically (quantitatively) equivalent to the human exposure

Biological plausibility

The mechanisms of developmental toxicity are understood, and the effects are biologically plausible

Modified from refs 20 and 74.

characteristics of the child. While some growth measurements are routine, many measurements taken by specialized counselors are not part of the usual physical examination, e.g., palpebral fissure size, ear length, intercanthal distances, and total height-to-trunk ratio. Important physical variations in facial, hand, and foor structure as well as other anatomical structures may be suggestive of known syndromes, either teratological or genetic.

\section{Evaluation of the reproductive risk or cause of a child's malformation after an environmental exposure during pregnancy}

The vast majority of consultations involving pregnancy exposures conclude that the exposure does not change the reproductive risks for that pregnancy. In many instances, the information that is available is so vague that the counselor cannot reach a definitive conclusion about the magnitude of the risk. The following information is necessary to evaluate any risk:

1 What was the nature of the exposure?

2 Is the exposure agent identifiable? If so, has it been definitively identified as a reproductive toxin with a recognized range of malformations or other reproductive effects?

3 At what stage during embryonic and fetal development did the exposure occur?

4 If the agent is known to produce reproductive toxic effects, was the exposure above or below the threshold for these effects?

5 Were there other significant environmental exposures or medical problems during the pregnancy?
6 Is this a wanted pregnancy or is the family ambivalent about carrying this baby to term?

7 What is the medical and reproductive history of the mother with regard to prior pregnancies and the reproductive history of the family lineage?

After obtaining this information, the counselor is able to provide the family with an estimate of the reproductive risks of the exposure. Some examples of consultations that have been referred to our clinical teratology service are listed below.

\section{Patient 1}

A 34-year-old pregnant laboratory worker dropped and broke a reaction vessel containing a mixture of chemical reagents. She proceeded to clean the floor with paper towels and later became concerned about the potential harmful effects of the exposure. This was a planned, wanted pregnancy; she was in the sixth week of pregnancy and, therefore, the embryo was in the period of early organogenesis. The chemicals in the spill were terrahydrofuran $(70 \%)$, pyridine $(20 \%)$, and iodine $(1 \%)$. It was not possible to quantitatively estimate the exposure to these agents, but the laboratory worker experienced no symptoms from the exposure. There have been no epidemiological studies of tetrahydrofuran and pyridine in pregnant women but iodine has been shown to interfere with fetal thyroid development; in this situation, however, the exposure would have been inconsequential because, at this stage of pregnancy, the thyroid is not yet present. No other exposure to reproductive toxins occurred in this pregnancy and the family history for congenital malformations was negative. The woman was advised that it would be very unlikely that her 
teratogenic risk would be increased because the exposures to the embryo would be extremely low. She was told that she still faced the background risks for birth defects and miscarriage and, therefore, her reproductive risks would be the same as that of the general population (Table 15.1).

\section{Patient 2}

A 26-year-old pregnant woman was in an automobile accident in the 10th week of her pregnancy and sustained a severe concussion. Although she did not convulse post injury, the treating neurosurgeon prescribed $300 \mathrm{mg}$ of diphenylhydantoin during her first $24 \mathrm{~h}$ in hospital. Fortunately, she recovered from the injury without any sequelae but her primary physician was concerned that she had received an anticonvulsant associated with a teratogenic syndrome. No other exposure to reproductive toxins occurred in this pregnancy and the family history for congenital malformations was negative, except for an uncle with neurofibromatosis. The primary physician requested a consultation with regard to the teratogenic risk. While diphenylhydantoin administered chronically throughout pregnancy has been associated with a low incidence of characteristic facial dysmorphogenesis, reduced mentation, cleft palate, and digital hypoplasia, there are no data to indicate that $24 \mathrm{~h}$ of therapy would cause any of these features. In addition, the development of the lip and palate are complete by the 10 th week of pregnancy. This was a wanted pregnancy and the mother chose to continue her pregnancy; she delivered a normal 3370-g boy at term.

\section{Patient 3}

A 25-year-old woman was seen in the emergency service of her local hospital with nausea, vomiting, and diarrhea, on return from a cruise on which a number of the passengers became ill with similar symptoms. The emergency-ward physician ordered a pregnancy test followed by a flat-plare radiograph of the abdomen as there was evidence of peritoneal irritation; however, both of these tests were negative. One week later she missed her menstrual period and a subsequent pregnancy test was positive. Her obstetrician was concerned because she had been exposed to a radiological examination at a time when she was pregnant; he referred the patient for counseling after obtaining an ultrasound that indicated that the embryo was approximately 7 days post conception at the time of the examination. The patient advised the counselor that she was ambivalent about the pregnancy because of the "dangers" of the X-rays to her embryo. The estimated exposure to the embryo was less than $500 \mathrm{mrad}(0.005 \mathrm{~Sv})$, an exposure that is far below that known to affect the developing embryo. Also, the embryo was exposed during the first 2 weeks post conception, a time that is less likely to increase the risk of teratogenesis, even at much higher exposures. ${ }^{3,70}$ Afrer an evaluation of the family history and after receiving counseling about the risks of the radiological examination, the woman decided to continue the pregnancy; she delivered a normal 3150-g baby.

\section{Evaluation of the cause of a child's congenital malformations: unknown, genetic, or environmental}

\section{Patient 4}

The mother of a 30-year-old man born in the Azores in 1960 with a congenital absence of the right leg below the knee had pursued compensation for her son because she was certain that she must have received thalidomide during her pregnancy. ${ }^{4}$ The German manufacturer of thalidomide refused compensation, claiming that thalidomide had never been distributed in the Azores. The mother fervently believed that thalidomide was responsible for her son's malformations and asked for my opinion; she sent me the radiograph studies of his hips and legs and his complete evaluation performed at the local hospital in the Azores. He had none of the other stigmata of thalidomide embryopathy (preaxial limb defects, phocomelia, facial hemangioma, ear malformations, deafness, crocodile tears, ventricular septal defect, intestinal or gallbladder atresia, and kidney malformations) and, most importantly, his limb malformations were not of the thalidomide type; he had a unilateral congenital amputation with no digital remnants at the end of the limb, his pelvic girdle was completely normal, and his limb defect involved only one leg with the other leg being normal. In this particular case, the man had a congenital amputation probably resulting from vascular disruption of an unknown etiology (known causes of vascular disruptive malformations are cocaine, misoprostol and chorionic villous sampling). It is difficult to determine whether any amount of appropriate counseling will give closure to this mother.

\section{Patient 5}

The family of a malformed boy claimed that the antinausea medication doxylamine succinate (Bendectin), ${ }^{52,53,71}$ taken by the mother during pregnancy, was responsible for the child's congenital limb reduction defects. Bendectin was taken after the period of limb organogenesis; however, some limb malformations can be produced by teratogens after this time. The boy's malformation was the classical split-hand, split-font syndrome, which is dominantly inherited; it was unaccompanied by any other dysmorphogenetic effects. Although significant number of cases of this syndrome result from a new mutation, neither parent manifested the malformation and this suggested that a new mutation had occurred in the sex cells of one of the parents. Therefore, the risk of this malformation occurring in the offspring of this boy would be $50 \%$. It was concluded that Bendectin was not responsible for this child's malformation; however, in spite of the obvious genetic etiology of the birth defect, a legal suit was filed. A jury decided for the defendant, namely, that Bendectin was not responsible for the child's malformation.

\section{Patient 6}

A woman visited a hospital emergency ward with severe lower abdominal pain; as she had had a previous ectopic pregnancy 
that necessitated the removal of her ovary and fallopian tube, she was seen by an obstetrical resident. A pregnancy test was positive and she returned to the obstetrical clinic a week later ; when her chorionic gonadotropin level was retested. It had not changed from its previous level and, without performing

' an ultrasound, a diagnosis of ectopic pregnancy was made; in order to preserve the patient's reproductive potential, it was decided to treat the ectopic pregnancy with methotrexate rather than remove the remaining fallopian tube and ovary. However, following the administration of methotrexate, a laboratory report was received which indicated that the gonadotropin level had increased fivefold, and a subsequent ultrasound revealed a normally implanted embryo; the laboratory report received earlier in the day was found to be a copy of the original report performed a week earlier. The mother was counseled that the baby was at an increased risk of having congenital malformations because of the exposure to methotrexate; however, she refused to abort the pregnancy. The obstetrical department therefore offered to provide care for the pregnancy and delivery that included a number of ultrasound examinations. At 28 weeks, the patient went into labor and delivered a premature liveborn infant, and during infancy, the child was diagnosed with hydrocephalus, developmental delay, and spastic cerebral symptomatology. The family filed a lawsuit against the doctors and hospital and I was asked to evaluate the allegation that the abnormalities in the child were due to the administration of methotrexate. Methotrexate has been reported to cause growth retardation, microcephaly, developmental delay, and hydrocephalus, but not prematurity. The clinical care provided by the resident doctor was unfortunate; however, the provision of care by the obstetrical department turned out to be fortunate for the defendants in this case. A review of the records revealed two important findings: first, an ultrasound examination taken a week before the premature delivery revealed that there was no evidence of hydrocephalus and, second, the birthweight was appropriate for the gestational stage. Therefore, the exposure to methotrexate was not responsible for the serious problems in this infant; the hydrocephalus and neurological symptoms resulted from a central nervous system (CNS) bleed in the postnatal period as a complication of the prematurity.

These examples show that it is not a simple process to determine the reproductive risks of an exposure during pregnancy or to determine the etiology of a child's congenital malformations. It requires careful analysis of the medical and scientific literature on the reproductive toxic effects of exoge- nous agents in humans and animals, as well as an evaluation of the exposure and biological plausibility of an increased risk or a causal connection between the exposure and a child's congenital malformation. It also involves a careful physical examination, and a review of the scientific literature regarding the genetic and environmental causes of the malformations in question. Abridged counseling, based on superficial and incomplete analyses, is a disservice to the families involved.

\section{Conclusion}

Approximately $10 \%$ of human malformations are due to environmental causes and fewer than $1 \%$ are related to prescription drug exposure, chemicals, or radiation. However, malformations caused by drugs and other therapeutic agents are important because these exposures may be preventable. Advances in animal research and epidemiology have enabled scientists to gain a better understanding of the mechanisms of teratogenesis.

Concerns about environmental chemicals and physical agents are clearly justified because, in most cases, not enough information is available on the potentially differential effects on the fetus and child. Such information, for example, the population exposure and the NOAEL, can only be obtained from high-quality human and animal toxicology and epidemiological studies which include toxicokinetic and toxicodynamic data and, therefore, it is essential that we expand our research programs in these areas. Ecological studies that do not measure exposures in the human population are more confusing than helpful in determining human risks, and studying exposures to groups of agents, e.g., solvents and pesticides, does not allow a risk assessment for individual toxicants.

All chemicals and drugs have the potential for developmental toxicity if the exposure is high enough; it would therefore be beneficial if humans were not exposed to chemicals in the workplace or home, or if chemicals were nor dispersed into the environment. To address this problem now, and in the future, an extensive program of monitoring, reducing, and eliminating the delivery of chemicals to the environment and the exposure of populations to chemicals is needed. Introducing or banning chemicals that expose the human population is an extremely difficult task that needs to be carefully planned on the basis of risks and benefits. 


\section{Key points}

1 Severe congenital malformations (including those birth defects that cause death, hospitalization, and mental retardation, and those that necessitate significant or repeated surgical procedures, are disfiguring, or interfere with physical performance) occur in $3 \%$ of all births.

2 Only a small percentage of birth defects are due to prescribed drugs, chemicals, and physical agents. Even when a drug is listed as a teratogen, it has to be administered during the sensitive period of development for that drug, and above the threshold dose for producing teratogenesis. Environmental causes account for approximately $10 \%$ of human birth malformations, and fewer than $1 \%$ of all human malformations are related to prescription drug exposure, chemicals, or radiation.

3 The etiology of congenital malformations can be divided into three categories: unknown $(65-75 \%)$, genetic (15-25\%), and environmental (10\%).

4 Reproductive problems alarm the public, press, and some scientists, to a greater degree than most other diseases.

5 Physicians must recognize the consequences of providing erroneous reproductive risks to pregnant women exposed to drugs and chemicals during pregnancy, or of alleging that a child's malformations are caused by an environmental agent without performing a complete and scholarly evaluation.

6 Labeling an environmental exposure as teratogenic is inappropriate unless one characterizes the exposure with regard to the dose, route of exposure, and stage of pregnancy when the exposure occurred.

7 The application of the basic scientific principles of teratology is extremely important in evaluating studies on the reproductive effects of an environmental agent. These principles include the following criteria: exposure to teratogens follows a toxicological dose-response curve; the embryonic stage at which exposure occurs determines what effects (if any) a teratogen has; most teratogens have a confined group of congenital malformations (syndrome of agent's effects) and; no teratogen can produce every type of malformation.

8 The risk of morphological anomalies or intrauterine death resulting from exposure to a developmental toxicant varies depending on the dose and the embryonic or fetal stage at which exposure occurs.

9 The threshold dose for an environmental toxicant is the dose below which the incidence of death, malformation, growth retardation, or functional deficit is not greater than that of control subjects. The severity and incidence of malformations produced by every exogenous agent that has been appropriately studied have exhibited threshold phenomena during organogenesis.
10 Teratogens follov a thesh old dose-response curve, whereas mutagen and inogens tend to follow a stochastic dose-response curve.

11 Physiological alte ations in pregnamey and the bioconversion of compolinds san signtifeantly influence the teratogenic eficus of un wgo and chicincais by affecting absorption, brity distribution, active form(s), and excretion of the comporsund.

12 Interpretation of dose-response relationships for teratogens must take into account the active metabolites, when metabolites might be the proximate teratogen rather than the administered drug or chemical, the duration of the exposure (chronic versus acute), and the fat solubility of the agent.

13 The role that the placenta plays in drug pharmacokinetics involves transport, the presence of receptors for a number of endogenous and xenobiotic compounds, and the bioconversion of xenobiotics.

14 The genetic constitution of an individual is an important factor that affect the susceptibility of a species to a drug or chemic

15 . Animal teratology studies a re helpful in raising concerns about the reproductive ettects of drugs and chemicals, but negative animal studies do not guarantee that these agents are free from reproductive effects.

16 Well-performed epidemiology studies represent the best methodology for determining the hurnan risk and the effects of environmental toxicants.

17 In vitro tests can be used to study the mechanisms of teratogenesis and embryogenesis, and for preliminary screening procedures. However, in vitro studies cannot predict human teratogenic risks at particular exposures without the bene of daca obsalue from who animal studies ar sndemiological udies.

18 The clinician must te cogntisutit of the fact that many patients believe that most congenital malformations are

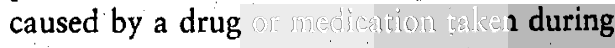
pregnancy.

19 Ignoring the basic tenets of watology appears to occur most commonly in the evaluation of environmental exposures when the exposure was very low or unknown and the agent has been reported to be teratogenic at a very high dose or maternally toxic dose.

20 The evaluation of the toxicity of drugs and chamicals should (when possible) use data obtained from investigative approaches including: (1) epidemiological studies, (2) secular trend analysis, (3) animal reproductive studies, (4) dose-response relationships, (5) mechanisms of action (MOA) studies that pertain specifically to the agent and include receptor affinity, cytotoxicity, genotoxicity, organ toxicity, and neurotoxicity, and (6) biological plausibility. 


\section{References}

1 Brent RL. Medicolegal aspects of teratology. J Pediatr 1967;71: 288-298.

2 Brent RL. Litigation-produced pain, disease and suffering: an experience with congenital malformation lawsuits. Teratology 1977; 16:1-14.

3 Brent RL. Utilization of developmental basic science principles in the evaluation of reproductive risks from pre- and postconception environmental radiation exposures. Teratology 1999;59:182-204.

4 Brent RL, Holmes L. Clinical and basic science lessons from the thalidomide tragedy: what have we learned about the causes of limb defects? Teratology 1988;38:241-251.

5 Brent RL. The irresponsible expert witness: a failure of biomedical graduate education and professional accountability. Pediatrics 1982;70:754-762.

6 Brent RL. Drugs and pregnancy: are the insert warnings too dire? Contemp Ob-Gyn 1982;20:42-49.

7 Wilson J. Environment and birth defects. New York: Academic Press, 1973.

8 Brent RL. Environmental factors: miscellaneous. In: Brent RL, Harris M, eds. Prevention of embryonic, fetal and perinatal disease. Bethesda, MD: John E. Fogarty International Center for Aduanced Study in the Health Sciences, NIH; 1976:211.

9 Heinonen $\mathrm{O}$, Slone $\mathrm{D}$, Shapiro S. Birth defects and drugs in pregnancy. Littleton, MA: Publishing Sciences Group, 1977.

10 Brent RL, Beckman D. Environmental teratogens. New York: New York Academy of Medicine, 1990.

11 Beckman D, Fawcett L, Brent RL. Developmental toxicity. In: Massaro E, ed. Handbook of human toxicology. New York: CRC Press; 1997:1007-1084.

12 Brent RL, Beckman D. Prescribed drugs, therapeutic agents; and fetal teratogenesis. In: Reece E, Hobbins J, eds. Medicine of the fetus and mother, 2nd edn. Philadelphia, PA: Lippincott-Raven Publishers; 1999:289-313.

13 Aase J. Diagnostic dysmorphology. New York: Plenum Medical Book Co., 1990.

14 Beckman D, Brent RL. Fetal effects of prescribed and selfadministered drugs during the second and third trimester. In: Avery G, Fletcher M, MacDonald M, eds. Neonatology: pathophysiology and treatment, 4th edn. Philadelphia, PA: JB Lippincott Co.; 1994:197-206.

15 Brent RL. What is the relationship between birth defects and pregnancy bleeding? New perspectives provided by the NICHD workshop dealing with the association of chorionic villous sampling and the occurrence of limb reduction defects. Teratology 1993;48: 93-95.

16 Brent RL, Beckman D. Teratogens: an overview. In: Knobil E, Neill J, eds. Encyclopedia of reproduction. New York: Academic Press; 1999:735-750.

17 Graham JJ, Jones K, Brent RL. Contribution of clinical teratologists and geneticists to the evaluation of the etiology of congenital malformations alleged to be caused by environmental agents, ionizing radiation, electromagnetic fields, microwaves, radionuclides, and ultrasound. Teratology 1999;59:307-313.

18 Jones K. Smith's recognizable pattern of buman malformations, 5th edn. Philadelphia, PA: WB Saunders Co., 1994.

19 Brent RL, Beckman D. Angiotensin-converting enzyme inhibitors, an embryopathic class of drugs with unique properties: information for clinical teratology councilors. Teratology 1991;43:543545 .
20 Brent RL. Methods of evaluating the alleged teratogenicity of environmental agents. In: Sever J, Brent RL, eds. Teratogen update: environmentally induced birth defect risks. New York: Alan R Liss; 1986:199-201.

21 Brent RL. Effects and risks of medically administered isotopes to the developing embryo. In: Fabro S, Scialli A, eds. Drug and chemical action in pregnancy. New York: Marcel Dekker; 1986:427439.

22 Brent RL. Radiation teratogenesis. Teratology 1980;21:281298.

23 Brent RL, Beckman D. Developmental effects following radiation of embryonic and fetal exposure to $x$-ray and isotopes: counseling the pregnant and nonpregnant patient about these risks. In: Hendee W, Edwards F, eds. Health effects of low levels exposure to ionizing radiation. Bristol \& Philadelphia: Institute of Physics Publishing; 1996:169-213.

24 Online Mendelian Inheritance in Man, OMIM'M. McKusickNathans Institute for Genetic Medicine, Johns Hopkins University (Baltimore, MD) and National Center for Biotechnology Information, National Library of Medicine (Berhesda, MD), 2000. World Wide Web URL: http://www.ncbi.nlm.nih.gov/omim/

25 Brent RL. Evaluating the alleged teratogenicity of environmental agents. In: Brent RL, Beckman D, eds. Clinics in perinatology. Philadelphia, PA: WB Saunders; 1986:609-613.

26 Brent RL. Protecting the public from teratogenic and mutagenic hazards. J Clin Pharmacol 1972;12:61-70.

27 Brent RL. Drug testing in animals for teratogenic effects: thalidomide in the pregnant rat. J Pediatr 1964;64:762-770.

28 Brent RL. The prediction of human diseases from laboratory and animal tests for teratogenicity, carcinogenicity, and mutagenicity. In: Lasagna L, ed. Controversies in therapeutics. Philadelphia, PA: WB Saunders; 1980:134-150.

29 Brent RL. Predicting teratogenic and reproductive risks in humans from exposure to various environmental agents using in vitro techniques and in vivo animal studies. Cong Anomalies 1988; 28(Suppl.):41-55.

30 Christian M, Brent RL. Teratogen update: evaluation of the reproductive and developmental risks of caffeine. Teratology 2001;64: 51-78.

31 Brent RL. Scientific frontiers in developmental toxicology and risk assessment (Review). Teratology 2002;65:88-96.

32 Brent RL. Teratogen update: reproductive risks of leflunomide (Avara). A parimidine synthesis inhibitor: counseling women lacking leflunomide before or during pregnancy and men taking leflunomide who are contemplating fathering a child. Teratology 2001;63:106-112.

33 Carter C. Genetics of common single malformations. Br Med Bull 1976;32:21-26.

34 Fraser $F$. The multifactorial/threshold concept: uses and misuses. Teratology 1976;14:267-280.

35 Boue J, Boue A, Lazar P. Retrospective and prospective epidemiological studies of 1500 karyotyped spontaneous abortions. Teratology 1975;12:11-26.

36 Herrig A. The overall problem in man. In: Benirschke K, ed. Comparative aspects of reproductive failure. Berlin: Springer-Verlag; 1967:11.

37 Simpson J. Genes, chromosomes and reproductive failure. Fertil Steril 1980;33:107-116.

38 Sever J. Infections in pregnancy: highlights from the collective perinatal project. Teratology 1982;25:227-237.

39 Briggs $M$, Briggs $M$. Sex hormone exposure during pregnancy and malformations. Adv Steroid Biochem Pharmacol 1979;7:51-89. 
40 Hochner-Celnikier D, Marandici A, Iohan F, Monder C. Estrogen and progesterone receptors in the organs of prenatal Cynomolgus monkey and laboratory mouse. Biol Reprod 1986;35:633-640.

41 Wilson J, Brent RL. Are female sex hormones teratogenic? Am J Obstet Gynecol 1981;141:567-580.

42 Jackson M. Drug absorption. In: Fabro S, Scialli A, eds. Drug and chemical action in pregnancy: pharmacologic and toxicologic. principles. New York: Marcel Dekker; 1986:15.

43 Mattison D. Physiologic variations in pharmacokinetics during pregnancy. In: Fabro S, Scialli A, eds. Drug and chemical action during pregnancy: pharmacologic and toxicologic principles. New York: Marcel Dekker; 1986:37-102.

44 Sonawane B, Yaffe S. Physiologic disposition of drugs in the fetus and newborn. In: Fabro S, Scialli A, eds. Drug and chemical action in pregnancy: pharmacologic and toxicologic principles. New York: Marcel Dekker; 1986:103.

45 Juchau M, Rettie A. The metabolic role of the placenta. In: Fabro S, Scialli A, eds. Drug and chemical action in pregnancy: pharmacologic and toxicologic principles. New York: Marcel Dekker; 1986:153-169.

46 Yang H, Namkung M, Juchau M. Cytochrome P450-dependent biotransformation of a series of phenoxazone ethers in the rat conceptus during early organogenesis: evidence for multiple P450 isozymes. Mol Pharmacol 1988;34:67-73.

47 Fantel A, Person R, Juchau M. Niridazole metabolism by rat embryos in vitro. Teratology 1988;37:213-221.

48 Juchau M. Bioactivation in chemical teratogenesis. Annu Rev Pharmacol Toxicol 1989;29:165-187.

49 Miller R. Placental transfer and function: the interface for drugs and chemicals in the conceptus. In: Fabro S, Scialli A, eds. Drug and chemical action in pregnancy: pharmacologic and toxicologic principles. New York: Marcel Dekker; 1986:123.

50 Mirkin B. Maternal and fetal distribution of drugs in pregnancy. Clin Pharmacol Ther 1973;14:643-647.

51 McKusic V. Medelian inheritance in man: catalogs of autosomal dominant, autosomal recessive, and $x$-linked phenotypes, 8th edn. Baltimore, MD: Johns Hopkins University Press, 1988.

52 Brent RL. Bendectin: review of the medical literature of a comprehensively studied human non-teratogen and the most prevalent tortigen-litigen. Reprod Toxicol 1995;9:337-349.

53 Brent RL. Review of the scientific literature pertaining to the reproductive toxicity of bendectin. In: Faigman D, Kaye D, Saks $\mathrm{M}$, et al., eds. Modern scientific evidence: the law and science of expert testimony. St. Paul, MN: West Publishing Group; 1997: 373-393.

54 Brent RL. Microwaves and ultrasound. In: Queenan J, Hobbins J, eds. Protocols for high risk pregnancies, 3rd edn. Cambridge: Blackwell Scientific; 1995:37-43.

55 Brent RL, Gordon W, Bennett W, Beckman D. Reproductive and teratogenic effects of electromagnetic fields. Reprod Toxicol $1993 ; 7: 535-580$.
56 Friedman J, Polifka J. TERIS. The teratogen information system. Seattle, WA: University of Washington, 1999.

57 Scialli A, Lione A, Padget GKB. Reproductive effects of chemical, physical and biologic agents. Baltimore, MD: Johns Hopkins University Press, 1995.

58 Sever J, Brent RL. Teratogen update: environmentally induced birth defect risks. New York: Alan R Liss, 1986.

59 Sheperd T. Catalogue of teratogenic agents, 8th edn. Baltimore, MD: Johns Hopkins University Press, 1995.

60 Schardein J. Chemically induced birth defects. New York: Marcel Dekker, 1993.

61 Briggs G, Freeman R, Yaffe S. Drugs in pregnancy and lactation, 3rd edn. Baltimore, MD: Williams and Wilkins, 1990.

62 Miller R. How environmental hazards have been discovered: carcinogens, teratogens, neurotoxins, and others. Pediatrics 2004; 113:945-951.

63 Physicians Desk Reference, 57th edn: Medical Economics Co. Montvale, NJ: Thomson Healthcare; 2003.

64 Friedman J, Little B, Brent RL, et al. Potential human teratogenicity of frequently prescribed drugs. Obstet Gynecol 1990;75: 594-599.

65 Dam K, Seidler F, Slotkin T. Transcriptional biomarkers distinguish between vulnerable periods for developmental neurotoxicity of chlorpyrifos: implications for toxicogenomics. Brain Res Bull 2003;59:261-265.

66 Tyl R, Myers C, Thomas B, et al. Three-generation reproductive toxicity study of dietary bisphenol $A$ in CD Sprague-Dawley rats. Toxicol Sci 2002;68:121-146.

67 Yamada H, Furuta I, Kato E, et al. Maternal serum and amniotic fluid bisphenol A concentrations in the early second trimester. Reprod Toxicol 2002;16:735-739.

68 Holson J, DeSesso J, Jacobson C, Farr C. Appropriate use of animal models in the assessment of risk during prenatal development: an illustration using inorganic arsenic. Teratology 2000;62:51-71.

69 Brent RL, Jensh R, Beckman D. Medical sonography: reproductive effects and risks. Teratology 1991;44:123-146.

70 Wilson J, Brent RL, Jordan H. Differentiation as a determinant of the reaction of rat embryos to x-irradiation. Proc Soc Exp Biol Med 1953;82:67-70.

71 Brent RL. Commentary on bendectin and birth defects: hopefully the final chapter. Birth Defects Res 2003;67:79-87.

72 Roberts $C$, Lowe C. Where have all the conceptions gone? Lancet 1975;1:498-499.

73 Brent RL. Editorial: definition of a teratogen and the relationship of teratogenicity to carcinogenicity. Teratology 1986;34:359-360.

74 Brent RL. Method of evaluating alleged human teratogens. Teratology 1978;17:83. 